\title{
The SMall RNA Regulators of ESCHERICHIA COLI: Roles and Mechanisms*
}

Susan Gottesman

Laboratory of Molecular Biology, National Cancer Institute, Bethesda, Maryland 20892; email: susang@helix.nih.gov

Key Words Hfq, DsrA, OxyS, RyhB, Spot 42

- Abstract Small noncoding RNAs have been found in all organisms, primarily as regulators of translation and message stability. The most exhaustive searches have taken place in E. coli, resulting in identification of more than 50 small RNAs, or 1\%-2\% of the number of protein-coding genes. One large class of these small RNAs uses the RNA chaperone Hfq; members of this class act by pairing to target messenger RNAs. Among the members of this class are DsrA and RprA, which positively regulate rpoS translation, OxyS, which negatively regulates $r p o S$ translation and fhlA translation, RyhB, which reapportions iron use in the cell by downregulating translation of many genes that encode Fe-containing proteins, and Spot 42, which changes the polarity of translation in the gal operon. The promoters of these small RNAs are tightly regulated, frequently as part of well-understood regulons. Lessons learned from the study of small RNAs in E. coli can be applied to finding these important regulators in other organisms.

\section{CONTENTS}

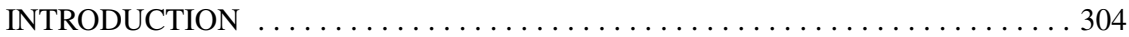

THE HISTORY AND RANGE OF sRNAs IN E. coli . . . . . . . . . . . . . . . . 304

Metabolic Labeling and Serendipity: The Classic Phase of sRNA

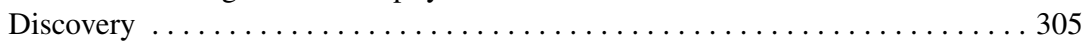

Computation and Global Detection: The Modern Phase of RNA Hunting . . . . . . 307 FUNCTIONAL CLASSES OF RNAs: AN EMPHASIS ON

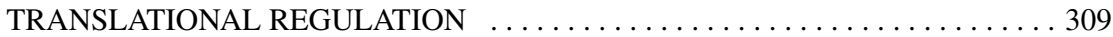

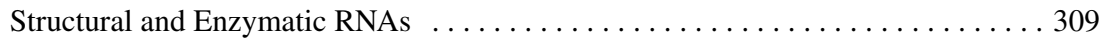

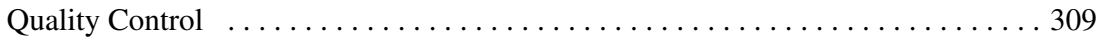

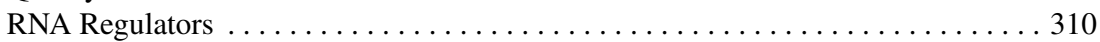

DEFINING A ROLE FOR Hfq IN sRNA FUNCTION . . . . . . . . . . 312

PHYSIOLOGICAL FUNCTION OF Hfq-BINDING sRNAs $\ldots \ldots \ldots \ldots \ldots \ldots \ldots . \ldots \ldots$

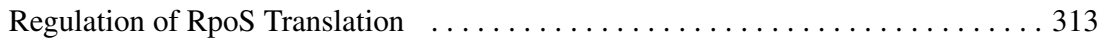

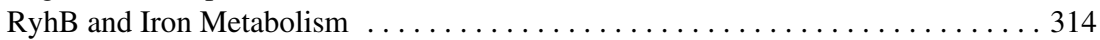

*The U.S. Government has the right to retain a nonexclusive, royalty-free license in and to any copyright covering this paper. 


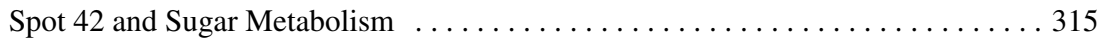

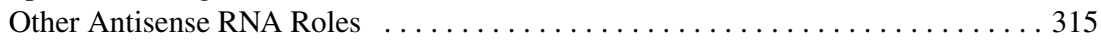

THE MECHANISM OF ANTISENSE RNA ACTIVITY . . . . . . . . . . . 316

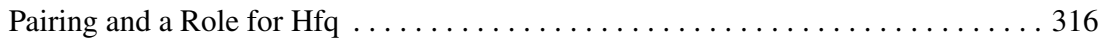

Outcomes of Pairing: Changing Translation and mRNA Stability . . . . . . . 317

Beyond Pairing: Role of RNase E in sRNA Action $\ldots \ldots \ldots \ldots \ldots \ldots \ldots \ldots . \ldots \ldots$

Our Current Picture of Antisense RNA Action: Summary and

Unsolved Problems . . . . . . . . . . . . . . . . . . . . . . . . . . 319

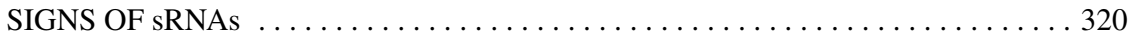

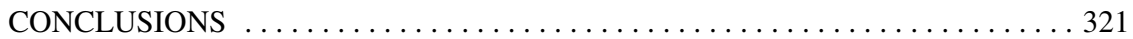

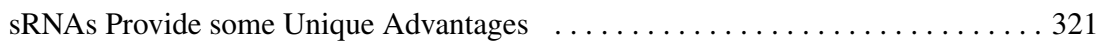

Where Did They Come From? . . . . . . . . . . . . . . . . . 321

\section{INTRODUCTION}

Escherichia coli is the organism in which researchers first identified and studied regulatory proteins, worked out most metabolic pathways, clearly recognized "regulons" and the concept of global regulatory networks, and first documented regulatory degradation of proteins. Decades of genetics, biochemistry, and, more recently, global analysis of gene expression have been documented for this organism. In the last few years, E. coli has again been in the forefront of a new field, the discovery and study of many new regulators, small noncoding RNAs. Small RNA regulators are proving to be multifunctional and have provided explanations for a number of previously mysterious regulatory effects.

Not surprisingly, this sort of regulator is not confined to E. coli. Phages and plasmids have long been recognized to use antisense RNA regulators (reviewed in References 21, 102); now these regulators are showing up in all bacterial cells, including pathogens. Quorum sensing in Vibrio species has now been shown to depend upon small RNA regulators (54a). In eukaryotic cells, microRNAs and RNAi parallel in many ways the bacterial small RNA regulators, confirming that this level of regulation is widespread and is as central to creating a working organism as are the protein regulators we are used to thinking about $(16,63)$. The intent of this review is to use what we have learned in studying small RNAs in E. coli to deduce some of the general principles of action and roles that these regulatory molecules are likely to play in other microorganisms. The focus is on the small subset of regulatory RNAs that have been most extensively studied. The broadest term for these molecules is noncoding RNA (ncRNA) (89). Because the bacterial noncoding RNAs are generally small, I refer to them here as sRNAs (small RNAs) or small regulatory RNAs.

\section{THE HISTORY AND RANGE OF sRNAs IN E. coli}

Most regulatory proteins were first identified by mutations that perturbed or abolished the regulation of a particular gene. More recently, genomic analyses have uncovered additional putative regulators, identified by their similarity to known 
regulatory proteins. Neither of these approaches has contributed significantly to identification of sRNA regulators in bacteria. None of the sRNAs in E. coli was first found by mutation. Failure to identify sRNA regulators by classical genetics may be due to the small target size for mutagenesis, a resistance to inactivation by single nucleotide changes, and activities not always measured in studies with transcriptional reporters. The standard sequence analysis to identify open reading frames (ORFs) in genomes generally leaves the sRNAs unrecognized and unannotated. Therefore, developing ways of identifying novel sRNAs has been an important part of the recent work in this field. sRNAs have been most intensively hunted in $E$. coli, and as a result we have the clearest picture of the range of types and numbers of sRNAs in this organism. Even in E. coli, however, new approaches continue to uncover new regulatory sRNAs. Table 1 provides a summary of which sRNAs may be expected in bacterial genomes, grouped by functional class. If the sRNA is included in this table, then it meets two criteria:

1. It functions as an RNA directly, not as part of a message. One can imagine an RNA acting both as a coding RNA and as a functional RNA. One such example exists, in Staphylococcus aureus (reviewed in Reference 42). It is also clear that some RNA sequences that are parts of messages $\left[5^{\prime}\right.$ or $3^{\prime}$ untranslated regions (UTRs)] carry out important sensing and regulatory roles, changing their folding and behavior as a function of temperature or binding to small molecule effectors $(43,88)$. However, although these are clearly RNA regulators, they act solely in cis and their mode of action is distinct enough that they will not be covered here.

2. The transcript is expressed. For the discussion here, that means that prediction by computational means or even detection by microarray is not yet considered adequate. Confirmation by Northern blot has been most generally used. Because the majority of these regulatory RNAs are small, we expect the transcript to be less than 300 nucleotides.

The entries in Table 1 were identified by a variety of approaches, discussed in more detail below. About 12 were found in what we can call the classic phase of sRNA discovery, either by direct labeling of RNAs or by chance during other work. More recently, in the modern phase of sRNA hunting, a variety of global approaches have expanded the list to over 50; others have been predicted computationally or detected by microarray but not confirmed by Northern blot.

\section{Metabolic Labeling and Serendipity: The Classic Phase of sRNA Discovery}

As the RNA species expressed by E. coli were first being cataloged, a number of abundant and frequently stable RNAs were identified by metabolic labeling and direct analysis by various fractionation procedures. These included RNAs such as the 4.5S RNA, part of the secretion machinery, and the 10S RNA, later found to be the catalytic part of the RNase P ribozyme (10Sb, encoded by rnpB). TmRNA, 


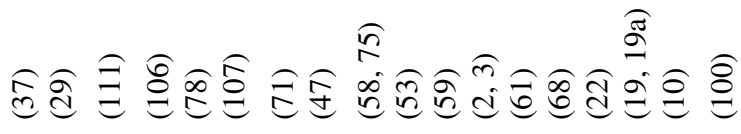

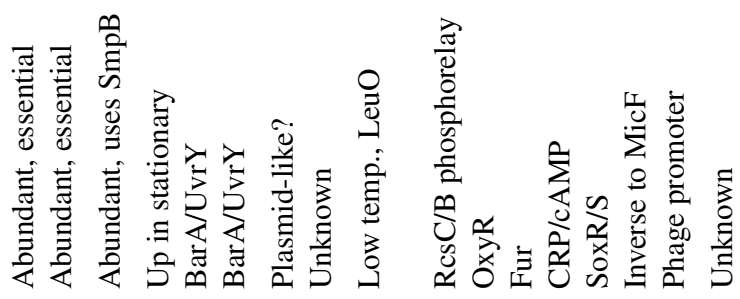

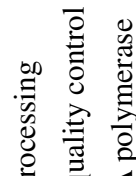

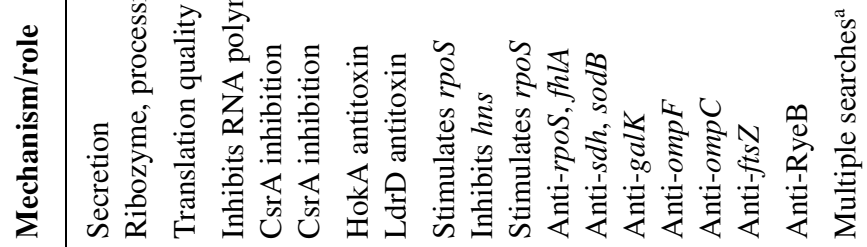

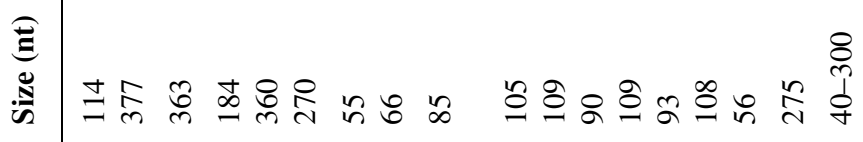

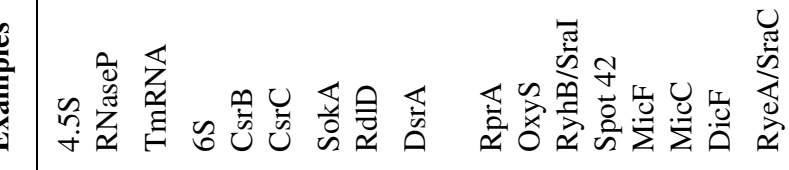

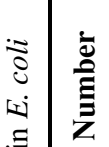

a $-m a$ ก m

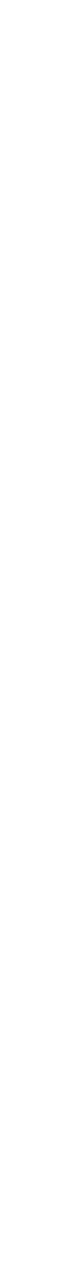

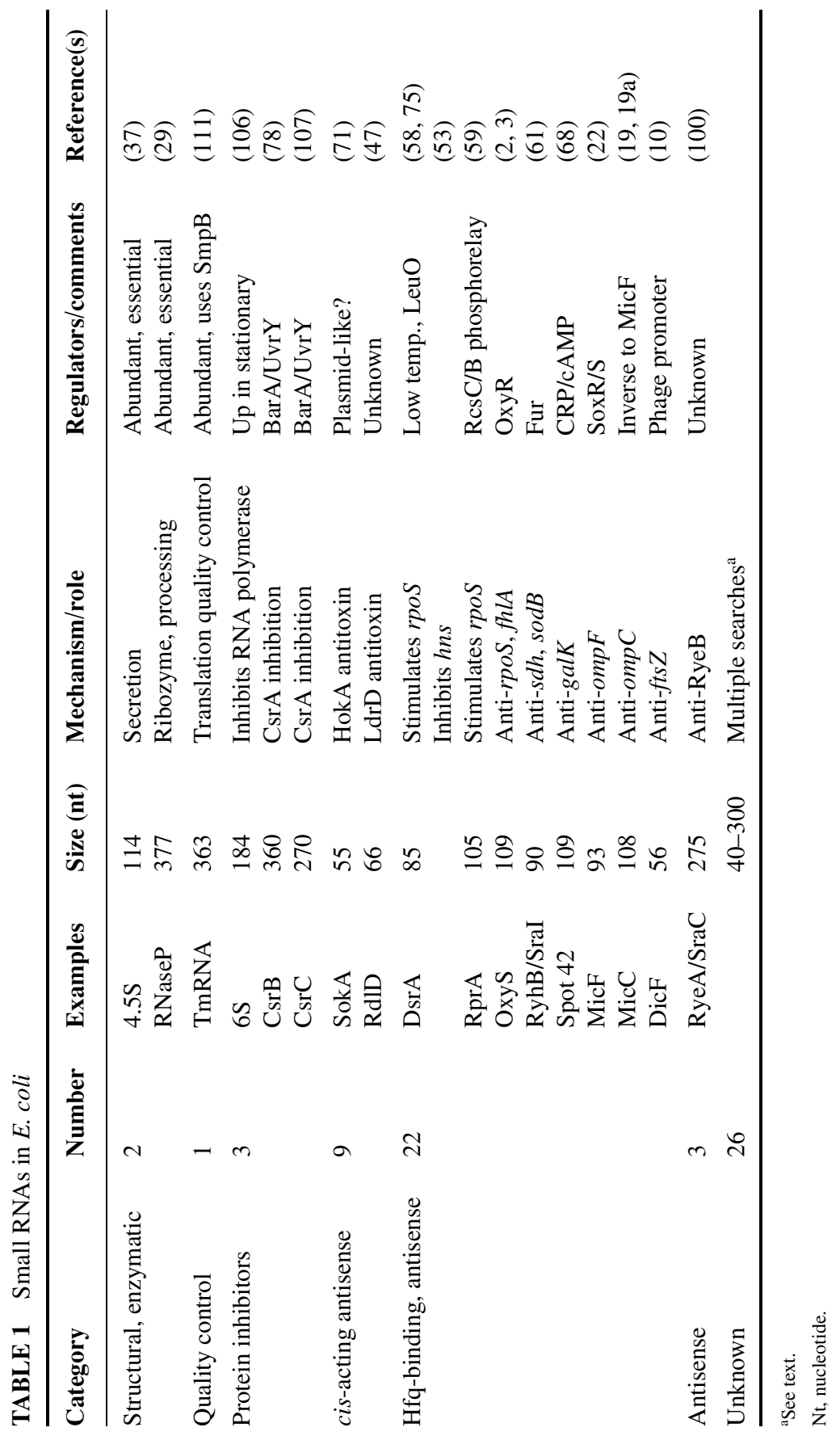


which serves an important role in translational quality control (see below), was initially identified as an RNA of a size similar to RNase P RNA (10Sa RNA, encoded by $s s r A$ ) (54). 6S RNA, which modulates RNA polymerase activity, and Spot 42, a sRNA that acts as an antisense regulator (see below), were also detected by metabolic labeling (39). Clearly, this approach favors relatively abundant and/or stable RNAs.

The small regulatory RNAs first studied in E. coli were found by accident, by observation of phenotypes conferred by multicopy plasmids or by detection of RNAs during the study of particular operons. Observation that a multicopy plasmid encoding the porin OmpC also downregulated expression of a second porin, OmpF, led to discovery of micF, transcribed divergently from ompC (4, 64). The regulatory RNAs OxyS and GcvB were detected as transcripts made divergently from the genes for the LysR family regulatory proteins OxyR and GcvA in transcription studies $(2,97)$. The synthesis of these sRNAs is regulated by the divergent regulator protein in a manner analogous to other LysR family proteins that regulate divergent protein-encoding genes (82). DsrA was identified during studies of capsule regulation as a gene capable of increasing capsule synthesis when present on a multicopy plasmid being studied for other reasons (84). Another sRNA, RprA, was identified in a screen of a multicopy plasmid library for plasmids that suppressed a phenotype of a $d s r A$ mutant (57). CsrB was found as a prominent and stable RNA species that binds to the translational regulatory protein CsrA (56). DicF, which inhibits fts $Z$ translation, is encoded within a cryptic prophage. It was found by analysis of plasmids encoding another prophage function, $\operatorname{dic} B$, when growth inhibition was present, even when $\operatorname{dic} B$ was absent (10).

\section{Computation and Global Detection: The Modern Phase of RNA Hunting}

RNA PREDICTIONS The more we learn about the sRNAs, the closer we come to defining characteristics that will allow us to predict them from the genome sequence of an organism. The set of sRNAs found by metabolic labeling and by serendipity had some characteristics in common. These properties have served as a guide in further searches. With the exception of 6S RNA and dicF, sRNAs are transcribed from single gene operons. These operons (and therefore the RNAs themselves) frequently end with a rho-independent terminator (seen at the DNA level as an inverted repeat followed by a run of Ts); other stem-loops are frequently seen in the predicted structure of these RNAs. They are encoded in intergenic regions (that is, between protein coding genes). Finally, these sRNAs are highly conserved in organisms such as Salmonella and Klebsiella. These properties were used in four different global hunts for novel sRNAs. The classes of RNAs found in these searches are summarized in Table 1.

Two groups have searched within intergenic regions for conservation with near relatives (Klebsiella and Salmonella, primarily). One of these groups (105) used location of the conservation within the intergenic region, expression detected on 
microarrays, and elements of structure to choose among conserved candidates for Northern blot confirmation. Another group (77) developed computational approaches to detect conservation of secondary structure (inverted repeats encoding stem-loops) within intergenic regions. Two other groups $(5,19)$ used computational methods to predict a promoter and a terminator within a given intergenic region with an orientation and spacing consistent with a sRNA (orphan promoters, terminators); Argaman et al. also demanded conservation for the predicted sRNA. Another group (17) carried out a purely computational search in E. coli using the characteristics of known ncRNAs in a learning program but did not extend the study to experimental confirmation of the large number of predicted ncRNAs.

GLOBAL ANALYSIS OF EXPRESSION Microarray analysis of transcripts from a given growth condition should reveal the existence of freestanding transcripts in places where no gene has been annotated. The first requirement is that the RNA be sufficiently expressed under the chosen growth condition to be detectable. This approach requires the use of arrays containing probes in the intergenic regions, currently available in Affymetrix oligonucleotide-based microarrays of E. coli. Signals detected on Affymetrix microarrays were used as secondary evidence in one conservation-based screen (105). In another study (94), a number of possible sRNAs were predicted on the basis of expression detected with the Affymetrix arrays in intergenic regions for 13 different growth conditions. Nineteen of 34 sRNAs known at the time were found in this analysis; 9 additional sRNAs were predicted, some of which have been identified as candidates in other searches. In a more recent search, RNAs bound to Hfq, an RNA chaperone previously implicated in the action of many regulatory RNAs (see below), were isolated by coimmunoprecipitation with $\mathrm{Hfq}$ and annealed to the microarray for identification; of 20 predicted Hfq-binding new sRNAs, 5 were confirmed by Northern blot (115). Notably, the new sRNAs that bind Hfq tightly were generally not well conserved, a probable explanation for the failure to detect them in the conservation-dependent searches and a warning that significant numbers of nonconserved but functional regulatory RNAs may exist.

Direct cloning of RNAs of a given size range is an approach that has been widely used to identify microRNAs in eukaryotic cells and archaea (16), and has also recently been applied to $E$. coli (100). This is the modern equivalent to the metabolic labeling studies done earlier; it requires nothing of the sRNA other than that it be expressed. Some of the cloned RNAs isolated by this approach are unique; others overlap with those detected by other methods. This approach may be useful for isolating sRNAs expressed at a high level under a given growth condition or for an organism for which microarrays are not available. In addition, only direct cloning is likely to find sRNAs encoded on the opposite strand to ORFs, unless a microarray with the other strand is specifically used. Even with this approach, sRNAs encoded on the sense strand of a gene are going to be difficult to distinguish from breakdown products of the relevant messenger RNAs without much further analysis. For now, such putative sRNAs may remain uncataloged. 
In summary, global approaches show that a significant number of sRNAs exist in the bacterial chromosome and that both computational and expression-based methods are productive in finding them; each has its limitations. The primary limitation of most methods of detecting sRNAs is a significant bias toward the intergenic region; sRNAs within genes, on either strand, are likely to be harder to detect.

There are approximately 4000 known ORFs in E. coli and 50-100 small regulatory RNAs (66 listed in Table 1). Thus, they represent about $2 \%$ of the number of protein-coding genes. Until searches for sRNAs have been carried out as thoroughly in other organisms, we will not know how typical this is. Even for E. coli, because each sRNA may regulate multiple target genes, it suggests a great many regulatory signals exist that we do not yet understand. For the majority of the RNAs in Table 1, little or nothing is known about function.

\section{FUNCTIONAL CLASSES OF RNAs: AN EMPHASIS ON TRANSLATIONAL REGULATION}

\section{Structural and Enzymatic RNAs}

Two highly conserved RNAs in Table 1 encode RNase P, an enzyme involved in processing tRNAs and rRNAs (29) and 4.5S RNA, used in secretion of cotranslationally secreted membrane and exported proteins (37). These two RNAs are also the only essential sRNAs currently known in E. coli. The involvement of these ncRNAs with the translation apparatus is echoed by the roles of many other sRNAs in translation quality control and translational regulation. Whether this reflects an evolutionary root in the translation machinery or the effectiveness of RNA:RNA interactions is not clear. However, in the absence of other information, it may be safe to assume that a given sRNA will act on message stability or translation.

\section{Quality Control}

One sRNA, tmRNA, is listed under Quality Control in Table 1. As with the structural RNAs, related RNAs are found in a wide range of other bacteria, as well as in the mitochondrial genomes of some eukaryotes $(109,110)$. The name tmRNA reflects its properties as both a tRNA and an mRNA; it is also called SsrA, a name that reflects its first detection (small stable RNA) (54). It was recognized to have portions of its structure that folded like tRNAs, and, like a tRNA, it could be charged with an amino acid (alanine) (51). Surprisingly, a group studying truncated versions of a cloned interferon protein found C-terminal extensions of 11 amino acids not encoded by the interferon gene and corresponding to a very short (10-amino-acid) coding region within the $s s r A$ gene (96). This work led to our current model of tmRNA action as part of the process of quality control of translation (48). Normally, protein translation stops when the ribosome encounters a nonsense 
codon. Not only does this cause a stop in translation, it also invokes the action of termination factors, leading to release of the finished polypeptide. If translation stalls or stops without a termination codon, for instance because the message stops prematurely or rare codons are present, tmRNA can enter the empty A site of the ribosome, the charged alanine on the tRNA portion of tmRNA is transferred to the stalled polypeptide chain, and translation resumes, but from the 10-amino-acid ORF internal to the tmRNA. Translation ends at the nonsense codon within the tmRNA reading frame, releasing a polypeptide with an 11-amino-acid C-terminal tag (the SsrA tag). This sequence is sufficient to direct the polypeptide to one of a number of energy-dependent proteases, usually ClpXP, rapidly clearing the cell of this presumably abnormal polypeptide $(31,36)$. This also clears the otherwise stalled ribosome, and a variety of evidence suggests that this function is at least as important as destroying the polypeptide. tmRNA requires the SmpB protein, which binds to the ribosome and helps deliver the tmRNA (46, 98). (For recent reviews and a more detailed discussion, see References $28,45,111$.)

\section{RNA Regulators}

The majority of the ncRNAs in Table 1 probably function as regulatory molecules. For a protein or an RNA to act as a regulator, it must have the following characteristics, discussed in more detail below:

1. Synthesis and/or activation only under specific conditions. For the sRNAs studied thus far, synthesis in response to a stress allows the regulatory switch to be turned on. Another class of RNA regulators, 5' UTRs that act as ribosensors, bind small molecule effectors; binding results in changes in the folding of the RNA and therefore changes transcription termination or translational activity (reviewed in References 88, 108). It seems quite possible that some sRNAs will also be found to be regulated and/or to act by binding to small molecules. Changes in folding as a result of intracellular conditions (temperature, osmotic strength) may also act as regulatory signals.

2. Specificity of action. For the sRNAs, sequence and structure may both contribute to specificity, with many sRNAs acting by complementary pairing with a target RNA.

3. Limited action. Every regulator needs to be shut off at an appropriate time. Synthesis can be shut down, but in addition activity should be lost as well when the activation signal is gone. At least some of the sRNAs appear to be inactivated by degradation associated with their activity; they may work stoichiometrically rather than catalytically (60). It remains to be seen if this is a universal property of these sRNAs and, if not, what other mechanisms exist to limit action.

RNAs THAT REGULATE PROTEIN ACTIVITY A major category of regulatory RNAs are those that act by binding to a protein and modifying its activity. There are 
currently two known target proteins in E. coli regulated directly by sRNA binding: RNA polymerase, regulated by binding to the 6S RNA (106), and CsrA, the carbon storage regulatory protein, regulated by binding to at least two RNAs, CsrB and CsrC $(56,107)$. These RNAs are discussed only briefly here, but both clearly represent well-conserved families of regulatory RNAs.

6S RNA is made in increased amounts as cells enter stationary phase and, almost unique among the well-studied sRNAs, is processed from the mRNA for an ORF of unknown function (38). 6S RNA is unique in another way as well, as it is the only known sRNA that acts on the transcription process rather than posttranscriptionally. Although mutations that eliminate $6 \mathrm{~S}$ have no strong phenotype, they do show a change in RNA polymerase promoter selectivity (106). Because 6S RNA binds to and inhibits RNA polymerase containing the vegetative sigma factor (sigma 70) but not that containing the stationary phase sigma factor (sigma 38 or RpoS), it seems to help alter promoter recognition during stationary phase. The structure of 6S RNA, which is well conserved, has been suggested to resemble a sigma 70 promoter, providing a basis for $6 \mathrm{~S}$ binding to polymerase and suggesting that binding should be within the promoter-binding regions of RNA polymerase (106).

$\mathrm{CsrA}$ is a protein that acts as a translational regulator. It binds sequences in the $5^{\prime}$ UTR of its target mRNAs to inhibit translation, redirecting carbon utilization. $\mathrm{CsrB}$ and $\mathrm{CsrC}$ are RNAs; each contains repeating sequence motifs, each capable of binding CsrA and resembling the sequence that CsrA binds in its target mRNAs (reviewed in Reference 78). Both the protein target, CsrA, and the sRNAs are widely found in gram-negative species and affect pathogenesis, biofilm formation, and swarming $(34,41,42,55)$. Regulatory signals for synthesis and degradation of this class of sRNAs are just beginning to be defined $(18,32,72,92)$.

RNA:RNA PAIRING FOR SPECIFICITY OF ACTION A significant number of the sRNAs in Table 1 are believed to act as antisense regulators, meaning that they work by pairing to messenger RNAs, affecting stability or translation of the message.

A few antisense RNA regulators are encoded on the opposite strand of the DNA from the regulated mRNA (cis-acting), resulting in the potential for complete pairing. This is akin to plasmid- and phage-encoded antisense molecules $(11,102)$. We assume that for these, the functional regulatory RNA has as its only target this cis-encoded transcript, although this need not be the case.

Some bacterial cis-acting RNAs, such as SokA and RdID (Table 1), are also similar in function to one class of antisense RNAs found in plasmids. They negatively regulate the expression of a toxin and therefore are components of what have been called toxin/antitoxin systems (reviewed in Reference 26). Although the function of these chromosomally encoded toxins is still a matter of debate, in plasmids they contribute to plasmid stability by killing plasmidless cells. Loss of the plasmid DNA means no new antitoxin synthesis; the unstable antitoxin decays, triggering killing of the plasmidless host. For some of these systems, the antitoxin is an RNA that inhibits translation of the toxin, directly or indirectly; the antitoxin RNA is more unstable than the toxin messenger. 
The majority of the known bacterially encoded antisense RNAs are encoded far from their targets; the vast majority also bind to and require the RNA chaperone Hfq. Furthermore, a recent genomewide search for Hfq-binding RNAs may have come close to saturating the search for this class of RNAs (115). The remainder of this review focuses on the Hfq-binding class of sRNAs, all of which are believed to act as antisense RNAs. For a few RNAs in this large class, we understand how their expression is regulated and have identified at least some of their targets; other sRNAs of unknown function are being actively studied. However, even when all these are understood, this class of sRNAs represents only about one-third of the identified sRNAs in E. coli (115), so there are many other sRNAs about which we know even less.

\section{DEFINING A ROLE FOR Hfq IN sRNA FUNCTION}

Hfq was first identified as a biochemical activity, a host factor, along with ribosomal protein $\mathrm{S} 1$, required for the replication of the RNA phage $\mathrm{Q} \beta$ (9). It was found to bind strongly to RNA, particularly AU-rich single-stranded RNA. It is part of a complex operon that also includes the $a m i B$ and $m i a A$ genes involved in RNA modification as well as the $h f l K C$ genes, regulators of an ATP-dependent protease, FtsH. In studies of this operon, Winkler and colleagues created insertion mutations in $h f q$ (95). The properties of the $h f q$ mutants led to recognition that Hfq was necessary for translation of RpoS, the stress sigma factor of E. coli (69). Hfq was shown to be important for overcoming an inhibitory hairpin upstream of rpos (13) (see below and Figure 1A, color insert). The hairpin occludes ribosome binding to the RpoS translation start site; the bypass mutants abolish the hairpin so that translation is constitutive (see Figure $1 A$ and below).

Independently, two sRNAs, DsrA and OxyS, were found to regulate rpoS translation $(2,85)$. Both sRNAs were found to bind Hfq and require it for their activity $(86,113)$. These sRNAs act by pairing with complementary sequences in their mRNA targets, suggesting that Hfq is important for this pairing. This was demonstrated in vitro for OxyS (114) and for another pairing sRNA, Spot 42 (67).

The class of Hfq-binding RNAs is large and contains some of the best-understood small regulatory RNAs. In a test of 46 known sRNAs found in various searches, 15 were found to bind Hfq tightly; at least 5 other sRNAs were defined by their binding to Hfq, bringing the total to at least 22, and possibly as many as 36 (115). Most likely, these all act by pairing to target messages. How Hfq acts to promote their action is discussed below in light of the best-studied cases.

\section{PHYSIOLOGICAL FUNCTION OF Hfq-BINDING sRNAs}

Four small Hfq-binding RNAs, DsrA, OxyS, Spot 42, and RyhB, have been studied in some detail. Experiments with each of them provide different insights into how the Hfq-binding RNAs can act. 
All four of these RNAs are approximately 100 nucleotides in length. Each is encoded by a freestanding gene with a single promoter, and each ends with a rho-independent terminator. The promoters resemble standard promoters but are all tightly regulated; only when synthesis is induced will a given sRNA have a significant biological effect. Computer predictions and probing of the structures of the RNAs in vitro suggests all are well structured; the longest single-stranded region is also the region in which Hfq binds (Figure 1).

What do the Hfq-dependent sRNAs do for cellular physiology? Many (but not all) are well conserved in related bacteria, suggesting an important function (and suggesting conservation of targets as well). There are very few cases in which the regulation of the RNA, the targets, and the physiological outcome are all well understood. I first review the regulatory circuits for the four RNAs listed above, followed by a discussion of the information currently available on their mechanism of action.

\section{Regulation of RpoS Translation}

The $r p o S$ gene encodes an alternative sigma factor, used by $E$. coli in times of stress (starvation, $\mathrm{pH}$ or osmotic shock, stationary phase) to transcribe large numbers of stress-response genes (reviewed in Reference 35). The RpoS response differs from some of the specific stress-response pathways in the range of signals that lead to its induction. RpoS levels are regulated primarily at the level of translation and at the level of protein turnover. The default state for $r p o S$ translation is "off;" only low levels of RpoS or of an rpoS-lac translational fusion are expressed under optimum growth conditions. This inhibition of translation depends on the structure of the mRNA upstream of the rpoS start codon. A long $5^{\prime}$ region can fold into a hairpin that inhibits ribosome binding. RpoS translation increases rapidly after stress treatments; this increase requires Hfq and, we now know, sRNAs. The inhibitory structure was defined by Brown \& Elliott (13) by searching for mutations that bypassed the Hfq requirement and made translation constitutive. As shown in Figure $1 A$ for DsrA, two sRNAs, DsrA and RprA, are complementary to the upstream stem of the hairpin and both activate translation of rpoS by pairing. Mutations in DsrA or RprA that disrupt pairing can be restored to function by compensating mutations in the rpoS RNA pairing target $(58,59)$. The $d s r A$ promoter is active only at low temperatures $\left(<30^{\circ} \mathrm{C}\right)(74,75)$. It is also negatively regulated by LeuO, although the physiological role of LeuO is not known $(50,74)$. Low temperature expression of DsrA leads to expression of RpoS during exponential growth at lower temperatures (85). Why is RpoS needed at low temperatures? Recent results show that products of the ots $A$ and $o t s B$ genes, which regulate levels of the osmoprotectant trehalose, protect the cell from cold temperatures (44). These genes are RpoSdependent. Therefore, low temperature leads to higher levels of RpoS, resulting in increased expression of these gene products and protection from very low $\left(4^{\circ} \mathrm{C}\right)$ temperatures. In addition, overexpressed DsrA negatively regulates $h n s$, encoding a pleiotropic transcriptional regulator $(52,84)$. HNS negatively regulates a number 
of genes that are osmotically inducible, and therefore DsrA negative regulation of hns may help the cell survive cold temperature and/or osmotic stress. There are other proposed targets of DsrA as well (52); it is unclear how they contribute to this physiological response.

RprA was found as a multicopy suppressor of $d s r A$ mutants (57). It is regulated via the phosphorelay cascade $\mathrm{RcsC} / \mathrm{YojN} / \mathrm{R} \operatorname{csB}$ (59). This cascade is responsible for regulation of capsule synthesis as well as regulation of some osmotically inducible genes, one of the many promoters of $f t s Z$, and a number of other genes as well $(14,20,27,33)$. The phosphorelay is activated by solid surfaces and regulates up to 150 genes, most associated with the cell membrane or cell surface (24), possibly all contributing to biofilm formation. Some genes regulated by activation of $\mathrm{RcsC}$ in recent global analyses could be indirect targets, regulated by RprA or by RpoS when it is positively regulated by RprA. Additional direct targets of RprA are likely to exist but have not yet been identified. Regulation of RpoS by DsrA and RprA is noteworthy as the only current example of positive regulation of a gene by a small antisense RNA. At least two other sRNAs have been identified that positively regulate RpoS translational fusions (105); the signals that lead to their induction have not been defined.

Changes in ionic strength affect RpoS translation by sRNAs without necessarily increasing the synthesis of the sRNAs (57); how this works is not yet clear (112).

Finally, negative regulation of RpoS induction by sRNAs also occurs. OxyS, regulated by OxyR and induced in response to oxidative stress, negatively regulates $\mathrm{RpoS}$ as well as a number of other targets, including fhlA (2). Because the same signals that lead to OxyS induction (activation of OxyR) also lead to induction of a set of genes that deal with oxidative stress, it has been suggested that this negative regulation shuts down less specific repair pathways in favor of the specific ones (113). FhlA activates synthesis of the formate hydrogenlyase complex in the presence of formate; metal cofactors for this might lead to $\mathrm{H}_{2} \mathrm{O}_{2}$-induced damage (2). The regulation of $f h l A$ by OxyS is direct, the result of antisense pairing both with the ribosome binding region and a second region within the fhlA gene (3) (Figure $1 B$ ). The mechanism of negative regulation of RpoS by OxyS is not understood.

\section{RyhB and Iron Metabolism}

RyhB RNA provides an answer to a puzzle in iron regulation, the positive regulation of some genes by the negative regulator Fur. Iron levels need to be carefully regulated because abundant iron can cause damage, but it is also an essential nutrient. In E. coli and many other bacteria, much of this regulation depends on the Fur protein, a repressor. When iron is plentiful, the Fur repressor binds $\mathrm{Fe}^{2+}$ and is active. When $\mathrm{Fe}^{2+}$ is limiting, Fur no longer represses, and the large number of genes in the Fur regulon are induced; these genes encode proteins involved in iron assimilation. Some genes, however, are positively regulated by Fur repressor and $\mathrm{Fe}^{2+}$. The positively regulated genes encode nonessential Fe-S proteins and ferritins, proteins that store $\mathrm{Fe}$; it makes sense to stop making these proteins when 
iron is limiting. But how does Fur act to positively regulate these genes? Studies on regulation of $\operatorname{sod} B$, encoding superoxide dismutase, one of these positively regulated genes, demonstrated that the regulation was posttranscriptional (23). When RyhB was found in a global search (105), examination of the literature and computer analysis suggested that it would be regulated by Fur and might pair with and regulate the $s d h$ operon, encoding another $\mathrm{Fe}-\mathrm{S}$ protein, succinate dehydrogenase. This proved to be the case; Fur negatively regulates $r y h B$, and RyhB negatively regulates $s d h$, $\operatorname{sodB}$ (see Figure $1 C$ ), and other Fe-S protein operons, leading to rapid degradation of the message for these operons (61). There is positive regulation of many operons encoding Fe-S proteins by Fe not only in E. coli (62) but also in other organisms, including mammals. Certainly some of this is due to RyhB-like molecules; in other cases, another mechanism of posttranscriptional regulation is used, the regulation of translation by the state of aconitase binding to $\mathrm{Fe}$ (reviewed in Reference 49).

\section{Spot 42 and Sugar Metabolism}

Another regulatory mystery, this time in the regulation of the gal operon, is also explained by a sRNA, Spot 42 . The ratio of UDP-galactose epimerase (product of galE, the first gene in the operon) to galactokinase (product of galK, the third gene in the operon) varies. When cyclic AMP is low, the ratio of GalE:GalK is high compared with growth under conditions that lead to high cyclic AMP; this effect is independent of the gal operon promoters. This makes physiological sense because although galactokinase is only needed when galactose is available to metabolize, UDP-galactose epimerase has a second role in synthesis of UDP-galactose, a building block for the cell wall and capsule (1). When cells are growing on glucose, cyclic AMP is low; galE but not galK translation is needed; on galactose, cyclic AMP levels are higher, but both galE and galK need to be translated. Spot 42, one of the first sRNAs to be identified (40), provides the link between CRP and cAMP and polarity in the gal operon. Spot 42 pairs with and negatively regulates translation of galK without perturbing galE translation (68) (Figure $1 D$ ). Spot 42 is made under the negative regulation of CRP and cAMP, leading to higher levels of sRNA synthesis when cells are growing on glucose and lower levels when cells are growing on less favorable carbon sources (80). Spot 42 also downregulates components of the suc operon, again playing a role in allowing different genes within an operon to be independently regulated; other targets may be found (1). Spot 42 is currently unique in its role in regulating polarity within an operon.

\section{Other Antisense RNA Roles}

A number of other sRNAs that act by antisense pairing have been studied and are described very briefly here. MicF RNA is made when the SoxR/S regulators are activated; it downregulates translation of one of the major porins, OmpF (reviewed in Reference 22). Recent work demonstrates that MicF binds Hfq strongly (115); 
presumably $\mathrm{Hfq}$ is necessary for its activity. A newly identified sRNA, MicC, regulates the other major porin, $\mathrm{OmpC}$, under complementary conditions (19a). These sRNAs presumably help the cell respond to environmental conditions beyond those that are sensed by the phosphorelay system that regulates both the ompF and ompC genes (73). Changing the ratio of OmpF to OmpC in the cell envelope modulates entry of small molecules into the cell.

DicF, encoded by a cryptic prophage, negatively regulates translation of the $f t s Z$ cell division gene. This sRNA, which is processed from a longer message, would not normally be expressed in a lysogen $(10,93)$. Possibly under conditions of prophage induction, inhibition of $f t s Z$ translation is useful for the inducing phage because encoded downstream from DicF is another cell division inhibitor, the DicB protein (8). DNA damage, used by many prophage as an inducing signal, also induces yet another inhibitor of FtsZ activity, SulA (104), suggesting a possible common theme in inhibiting cell division after DNA damage.

\section{THE MECHANISM OF ANTISENSE RNA ACTIVITY}

The group of RNAs discussed above all pair with their targets, and the specificity of action depends on that pairing (Figure 1). The extent of pairing that is needed and the nature of the initial interactions have not yet been studied in detail for any of these sRNAs. What is known suggests that one or two regions, each with 8-9 base pairs, are sufficient to allow specific regulation. The best-studied examples are the cis-acting sRNAs; in these, short regions of pairing can initiate interactions; these regions are frequently in the loops of stem-loops and may then extend to longer regions of interaction $(26,103)$. It seems likely the nature of the pairing for the trans-acting sRNAs will be similar.

\section{Pairing and a Role for $\mathrm{Hfq}$}

In vivo, all four of the sRNAs discussed above require Hfq for activity. How does Hfq act? Hfq is a well-conserved hexameric protein; electron microscopy and crystallography show that it forms a ring and has structural homology to eukaryotic Sm and Sm-like proteins that function in RNA splicing $(81,83,91)$. Hfq binds AU-rich single-stranded RNA, with a preference for binding next to a structured (stem-loop) region $(12,67,114)$ (see Figure 1). The single-stranded RNA binds to the inside of the ring along the top surface (83). Recent research on Hfq is reviewed in more detail in Reference 97a.

One effect of Hfq is clearly to increase the stability of the sRNAs. In vivo, when new RNA synthesis is stopped with rifampicin and stability is followed by Northern blots, these RNAs are frequently quite stable, with half-lives ranging from a few minutes to greater than $30 \mathrm{~min}$; most are considerably less stable in $h f q$ mutants $(60,67,100)$. Consistent with Hfq stabilization of these RNAs, there is a lower accumulation of many sRNAs in $h f q$ mutants (115). Thus, one role for Hfq could be just to stabilize the sRNAs. As expected from this model, overproduction of DsrA can partially bypass the requirement for Hfq (86). 
A variety of in vitro experiments suggests that Hfq has a more active role in stimulating sRNA activity than simply to stabilize the RNA substrates. Hfq is an RNA chaperone with the ability to stimulate splicing of a bacteriophage intron (66). Hfq also binds to the target mRNAs of the sRNAs. This has been determined both in vivo, where some messenger RNAs can be precipitated with Hfq (115), and in vitro, where a number of mRNA targets bind Hfq specifically. In some cases, this binding site is near the region involved in pairing $(25,67,99,114)$. Only modest effects of Hfq binding on stability of these messages have been detected (in the absence of the sRNA) (99). For ompA mRNA, stability of the message is greater in the absence of Hfq, which has been interpreted as interference with ompA translation by Hfq binding, coupled with protection of the ompA message from degradation by the act of translation (101). An alternative explanation would be that Hfq allows a yet unidentified sRNA to target the ompA message for translation inhibition and degradation, as would be seen, for instance, for the sodB message, also more stable in an $h f q$ mutant.

If Hfq is binding to both mRNA and sRNA, does it help to bring them together? In vitro, Hfq stimulates the pairing of both Spot 42 and OxyS to their target message $(67,114)$; recent experiments with RyhB show similar stimulation of pairing $(25)$. Two possible roles for Hfq in this stimulation of pairing have been suggested; both may be true. In one model, interactions between the RNAs and Hfq increase local concentrations, aiding RNA:RNA interaction. For instance, if one ring of Hfq binds to the regulatory RNA and another to the target message, interactions between the two rings could promote the interaction of the two RNAs. Because it is not clear how the right rings of Hfq would find each other, it seems likely that this Hfq:Hfq interaction, if it occurs, might stabilize interactions already taking place by direct RNA:RNA pairing. The second model suggests more of a chaperone role. Hfq binding to a sRNA or to a target may change and/or stabilize RNA structure in such a way that complementary sequences are more available for pairing. This has been studied in vitro in a few instances. Although Hfq binding did not change the structure of RyhB or DsrA, it did change the structure of the RyhB target $\operatorname{sodB}$, improving its ability to pair with RyhB $(12,25)$. Subtle changes in OxyS structure were detected on Hfq binding (114). Possibly Hfq also recruits other activities that have more direct roles in changing RNA structure. A recent paper suggests that Hfq itself has ATPase activity and that it associates with ribosomal protein S1 and, through that association, with RNA polymerase (90); this would suggest significantly more complex roles for Hfq.

\section{Outcomes of Pairing: Changing Translation and mRNA Stability}

Although all the sRNAs shown in Figure 1 act by pairing and require Hfq, they have different final effects on their targets. It is not known if this reflects essential differences in the way these sRNAs act. The effects of pairing discussed below are not mutually exclusive; changes in structure can lead to changes in translation and vice versa. 
Pairing can change folding of the target or sRNA. For the plasmid-encoded cis-acting sRNAs, this can affect transcription termination as well as translation and message stability (reviewed in References 11, 26, 30, 102).

Pairing can change ribosome accessibility. This may affect message degradation. In some cases, the pairing can improve ribosome accessibility, as it does for RpoS when positively regulated by DsrA (58). In one recent in vitro study, DsrA was found to bind directly to the $30 \mathrm{~S}$ ribosome (112); although such a binding activity might increase the local concentration of DsrA near a message about to be translated, it is not yet clear if this is necessary for DsrA activity in vivo. In the case of RyhB pairing with $\operatorname{sodB}$, in vitro tests demonstrated inhibition of translation, dependent on pairing (99). When the relevant ribosome access site is internal to an operon, the RNA can cause polarity, as with Spot 42 regulation in the gal operon (68).

Pairing can lead to rapid mRNA degradation, as observed with RyhB (60). We do not yet know if this degradation is indirect, a consequence of blocking ribosome access, but it clearly makes the process irreversible.

TURNOVER OF sRNAs AS A CONSEQUENCE OF PAIRING In addition to these effects on the target mRNA, pairing can lead to rapid degradation of sRNAs. This conclusion is currently indirect; RyhB, DsrA, and OxyS were rapidly degraded in the presence of ongoing transcription, although they are very stable in rifampicintreated cells (60). We interpret this to mean that these RNAs are degraded upon pairing with their mRNA targets. When new transcription is inhibited with rifampicin, the mRNA targets are degraded and no new ones are made; under these conditions, the sRNAs become stable. This rapid turnover as a consequence of pairing means that RyhB and the other small, pairing RNAs act stoichiometrically rather than catalytically and that they will only continue to act as long as the signals for their synthesis are present. Thus, this degradation during use provides an intrinsic shutdown mechanism.

\section{Beyond Pairing: Role of RNase E in sRNA Action}

Because a major outcome of pairing can be degradation of the sRNA and the target mRNA, how is this taking place? Mutations in $r n c$, encoding RNase III, a doublestranded endonuclease and the protein most like the ribonuclease in eukaryotes that processes RNAi and microRNAs (Dicer), had no effect on degradation of RyhB or its target mRNA (60). The other major endoribonuclease, RNase E, is an essential enzyme involved in processing many RNAs, most significantly tRNA, as well as RNase P and tmRNA. It is also involved in mRNA degradation; temperaturesensitive mutants in the active site affect the rate of turnover of mRNAs (reviewed in Reference 15). Finally, RNase E is the scaffold for assembly of a protein complex called the degradosome, made up of polynucleotide phosphorylase, enolase, and an RNA helicase, in addition to RNase E. Deletions of the degradosome-binding domain of RNase E are not lethal. 
Recent work on a number of systems suggests that RNase E plays a critical role in the functioning of Hfq-binding sRNAs. Intriguingly, the recognition motif for RNase E cleavage is a single-stranded AU-rich region, reminiscent of the sequences recognized by Hfq. It now has been shown that Hfq and RNase E at least sometimes see the same targets. RyhB becomes very unstable in an $h f q$ mutant (as do a number of other sRNAs) and is stabilized in an RNase E mutant $(60,65)$. In vitro, cleavage of RyhB by RNase E is inhibited by Hfq (65). Similar observations were made for DsrA (65), and the cleavage site for RNase E defined in vitro could give rise to a truncated DsrA RNA observed in vivo in other experiments (74). In a separate series of experiments, we found that certain processing intermediates of the transcript from the $\arg X$-proM tRNA operon bind Hfq near RNase E cleavage sites; processing by RNase E appears to be slowed when Hfq is present (115). In general, it seems safe to say that many, if not all, Hfq-binding sites have the potential to be RNase E cleavage sites and vice versa; the equilibrium between amounts and specific affinity may determine how much Hfq binding protects a given RNA from RNase E.

RNase $\mathrm{E}$ is required for the degradation of both mRNA and the sRNA (RyhB) in vivo $(60,65)$. sodB is normally degraded in an RNase E-dependent fashion, so that it is difficult to determine if the RyhB-stimulated degradation is secondary to blocking translation or a direct consequence of pairing. In either case, however, the degradation of sRNAs is also stimulated upon pairing. Possibly pairing changes or displaces Hfq binding, allowing RNase E or other degradosome components entry to sites that otherwise are shielded.

It is not yet clear how important the degradosome is for sRNA action. RyhB and $\operatorname{sodB}$ degradation are both slowed in degradosome mutants, although the specific roles of degradosome components has not been explored (60). It is tempting to suggest that helicase unwinding, for instance, will be particularly important in the degradation of the highly structured sRNAs, possibly after the initial endonucleolytic cuts are made.

\section{Our Current Picture of Antisense RNA Action: Summary and Unsolved Problems}

We can now put together a picture of the mode of action of Hfq-binding sRNAs. Thus far, all these sRNAs act by pairing with target mRNAs (Figure 1). Pairing is stimulated in vivo by Hfq, in part by binding to and stabilizing the sRNAs, but probably by more actively stimulating pairing. In most cases, negative regulation of the translation activity and stability of the message is a result of pairing. RNase E gains access to both message and sRNA, cleaving both; exonucleases then complete the degradation. How Hfq is displaced from the paired complex to allow RNase E attack is not yet known. In cases in which regulation is positive (sRNA stimulation of RpoS translation) or in which the mRNA is not degraded (Spot 42 regulation within the gal operon), destruction of the mRNA must be blocked. Whether this reflects differences in the nature of pairing, in the relative location of the 
Hfq-binding site and pairing regions, or other properties of either sRNA or message is not yet clear.

The model systems studied thus far provide only a glimpse at how these sRNAs work. In vivo studies identified Hfq's role in sRNA action. What other proteins are involved in this process? HU, a histone-like protein in E. coli, binds well to RNA, and mutants lacking HU have RpoS translation defects, suggesting a possible role for HU in sRNA function $(6,7)$. Hfq has been found associated with $\mathrm{S} 1$ both for $\mathrm{Q} \beta$ growth and in binding to RNA polymerase (90); they may also act together for sRNAs. Sequences required for optimal pairing within the sRNA and target messages have not been defined in most cases. Studies of plasmid antisense RNAs suggest that the details of the interactions will be critical in fully defining how these RNAs act.

Finally, in vivo competition between multiple targets for a given sRNA may be critical under some conditions, particularly because the sRNA can be consumed by pairing with one abundant target. Thus far, this has not been assessed in vivo and is missing from most in vitro studies.

\section{SIGNS OF sRNAs}

Now that we know they exist, we can be more alert to the signs that a sRA might be playing an important role in a given regulatory circuit. In cases where things do not quite fit, a sRNA may be lurking somewhere. Here are some examples:

1. Unexpected direction of regulation. RyhB provides an explanation for how Fur, a repressor, could positively regulate genes (see above). Fur negatively regulates RyhB; RyhB in turn negatively regulates a set of genes encoding iron-binding proteins. In general, for any known negative regulator, an observation of positive regulation could be due to a similar cascade; two negatives make a positive. Similarly, a positive regulator can act negatively on a target message by activating synthesis of a negatively regulating sRNA. Inverted regulation does not have to be via sRNAs, but because the sRNAs are generally missed in mutant hunts, it may take special attention to find them.

2. Orphan regulator binding sites. Genomewide definition of functional regulatory sites can be done by computational methods, by multicopy titration, or by genomewide mapping of regulatory protein binding sites by chromatin coimmunoprecipitation. If any of these approaches demonstrate a binding site for a regulator, and the nearby ORF does not show the appropriate regulation, this may be evidence of a regulatory site for a sRNA. In fact, sRNAs that are regulated by the Fur repressor in Pseudomonas aeruginosa were recently identified by locating a Fur binding site and a transcription terminator sequence in reasonable proximity in an intergenic region (116).

3. Regulation without a site. Some sRNAs lead to rapid degradation of their target messages; this should be detectable in experiments with arrays and 
in those with transcriptional fusions that contain the relevant sRNA target site. Therefore, we need to be aware that not every change in transcription is due to changes in synthesis. Evidence of regulation of a given gene in array experiments, for instance, coupled with failure to find a regulatory protein binding site in the relevant promoter, may indicate that regulation is indirect, via a sRNA.

4. Regulated translation. In a genomewide search for conservation in intergenic regions, many highly conserved 5' UTRs were observed (105). Hfq also binds to the message from many genes with $5^{\prime}$ UTRs (115). Although neither of these is evidence of a target for a sRNA, researchers should keep that possibility in mind.

\section{CONCLUSIONS}

\section{sRNAs Provide some Unique Advantages}

Why use a sRNA instead of a protein regulator? One advantage may be their size and therefore the speed of the response. Once synthesis starts, it takes very little time to complete the regulator. If it is degraded as it is used, no other mechanism for turnover is needed.

sRNAs that regulate translation also provide a simple way to impose an overarching level of regulation on a group of genes or operons that may be regulated in many different ways at the level of transcription. A sRNA acting at the level of translation or messenger stability will always be epistatic to transcriptional regulation of the same gene. This is most evident for RyhB, which can simultaneously downregulate many genes; if iron is limiting, this becomes necessary irrespective of the individual inducing signals for each of the genes. Multiple sRNAs, each made under different conditions, can regulate a single target, allowing integration of many environmental signals. Thus far, this is best exemplified by the sRNAs that regulate RpoS translation (76).

Other advantages are likely to appear as we learn more about these multitalented molecules. It seems likely that every major regulatory network will contain at least one sRNA. Recent reports on effects of $h f q$ mutants on virulence in many organisms suggest that these sRNAs will play critical roles in pathogenesis as well $(70,79$, 87).

\section{Where Did They Come From?}

The above arguments for the advantages of sRNAs imply that they are of value to current organisms and not simply a relic from the ancient "RNA world." In fact, we do not know whether any of these regulatory RNAs are relatively newly evolved or from where they have evolved. The Hfq-binding sRNAs are tRNA-like in size but apparently not in sequence or structure, and the widespread occurrence of Hfq suggests that the RNAs will be widespread as well. Sequence similarities 
can only be detected thus far between the Hfq-binding sRNAs from E. coli and its relatively close neighbors-Salmonella, Klebsiella, Yersinia, and Vibrio. Pseudomonas aeruginosa contains at least some functionally similar sRNAs with no apparent sequence similarity. Does this reflect rapid evolution from a common source, or convergent evolution? As we find them in more organisms, the nature or lack of relatedness should become more apparent and help us define the critical properties that are conserved across species.

As more sRNAs are identified, the challenge of finding out what they do will become even more pressing than it is now. The next few years are likely to see the development of new ways to study them and identify their targets, much as the past few years has led to new and better ways to find them. In the end, the network of connections between the components of an organism such as E. coli will need to include the RNA regulators in addition to the protein regulators if we will ever truly be able to predict how an organism will react under a given condition.

\section{ACKNOWLEDGMENTS}

I thank the many colleagues who shared unpublished results and provided invaluable discussions on the topics covered in this review. I thank Gisela Storz, Cari Vanderpool, David Fitzgerald, Karl Thompson, and Eric Massé for comments on the manuscript.

\section{The Annual Review of Microbiology is online at http://micro.annualreviews.org}

\section{LITERATURE CITED}

1. Adhya S. 2003. Suboperonic regulatory signals. Sci. STKE 185:22

2. Altuvia S, Weinstein-Fischer D, Zhang A, Postow L, Storz G. 1997. A small stable RNA induced by oxidative stress: role as a pleiotropic regulator and antimutator. Cell 90:43-53

3. Altuvia S, Zhang A, Argaman L, Tiwari A, Storz G. 1998. The Escherichia coli oxyS regulatory RNA represses fhlA translation by blocking ribosome binding. EMBO J. 17:6069-75

4. Andersen J, Delihas N, Ikenaka K, Green PJ, Pines O, et al. 1987. The isolation and characterization of RNA coded by the micF gene in Escherichia coli. Nucleic Acids Res. 15:2089-101

5. Argaman L, Hershberg R, Vogel J, Bejerano G, Wagner EGH, et al. 2001. Novel small RNA-encoding genes in the inter- genic region of Escherichia coli. Curr. Biol. 11:941-50

6. Balandina A, Claret L, Hengge-Aronis R, Rouviere-Yaniv J. 2001. The Escherichia coli histone-like protein $\mathrm{HU}$ regulates rpoS translation. Mol. Microbiol. 39:1069-79

7. Balandina A, Kamashev D, RouviereYaniv J. 2002. The bacterial histone-like protein HU specifically recognizes similar structures in all nucleic acids, DNA, RNA, and their hybrids. J. Biol. Chem. 277:27622-28

8. Bejar S, Bouche JP. 1985. A new dispensable genetic locus of the terminus region involved in control of cell division in Escherichia coli. Mol. Gen. Genet. 201:146-50

9. Blumenthal T, Carmichael GG. 1979. RNA replication: function and structure 
of $\mathrm{Q} \beta$-replicase. Annu. Rev. Biochem. 48:525-48

10. Bouché F, Bouché JP. 1989. Genetic evidence that DicF, a second division inhibitor encoded by the Escherichia coli $\operatorname{dicB}$ operon, is probably RNA. Mol. $\mathrm{Mi}$ crobiol. 3:991-94

11. Brantl S. 2002. Antisense-RNA regulation and RNA interference. Biochim. Biophys. Acta 1575:15-25

12. Brescia CC, Mikulecky PJ, Feig AL, Sledjeski DD. 2003. Identification of the Hfqbinding site on DsrA RNA: Hfq binds without altering DsrA secondary structure. RNA 9:33-43

13. Brown L, Elliott T. 1997. Mutations that increase expression of the $r p o S$ gene and decrease its dependence on $h f q$ function in Salmonella typhimurium. J. Bacteriol. 179:656-62

14. Carballes F, Bertrand C, Bouché JP, Cam K. 1999. Regulation of Escherichia coli cell division genes $f t s A$ and $f t s Z$ by the two-component system $r c s C$-rcsB. Mol. Microbiol. 34:442-50

15. Carpousis AJ. 2002. The Escherichia coli RNA degradosome: structure, function and relationship in other ribonucleolytic multienzyme complexes. Biochem. Soc. Trans. 30:150-55

16. Carrington JC, Ambros V. 2003. Role of microRNAs in plant and animal development. Science 301:336-38

17. Carter RJ, Dubchak I, Holbrook SR. 2001. A computational approach to identify genes for functional RNAs in genomic sequences. Nucleic Acids Res. 29:392838

18. Chatterjee A, Cui Y, Chatterjee AK. 2002. RsmA and the Quorum-sensing signal, N-[3-oxohexanoyl]-L-homoserine lactose, control the levels of $r s m B$ RNA in Erwinia carotovora subsp. carotovora by affecting its stability. J. Bacteriol. 184:4089-95

19. Chen S, Lesnik EA, Hall TA, Sampath R, Griffey RH, et al. 2002. A bioinformaticsbased approach to discover small RNA genes in the Escherichia coli genome. Biosystems 65:157-77

19a. Chen S, Zhang A, Blyn LB, Storz G. 2004. MicC, a second small RNA regulator of Omp protein expression in Escherichia coli. J. Bacteriol. In press

20. Davalos-Garcia M, Conter A, Toesca I, Gutierrez C, Cam K. 2001. Regulation of $\operatorname{osm} C$ gene expression by the two-component system $r c s B$-rcsC in Escherichia coli. J. Bacteriol. 183:587076

21. Delihas N. 1995. Regulation of gene expression by trans-encoded antisense RNAs. Mol. Microbiol. 15:411-14

22. Delihas N, Forst S. 2001. MicF: an antisense RNA gene involved in response of Escherichia coli to global stress factors. J. Mol. Biol. 313:1-12

23. Dubrac S, Touati D. 2000. Fur positive regulation of iron superoxide dismutase in Escherichia coli: functional analysis of the $\operatorname{sodB}$ promoter. J. Bacteriol. 182:3802-8

24. Ferrieres L, Clarke DJ. 2003. The RcsC sensor kinase is required for normal biofilm formation in Escherichia coli $\mathrm{K}$ 12 and controls the expression of a regulon in response to growth on a solid surface. Mol. Microbiol. 50:1665-82

25. Geissmann TA, Touati D. 2004. Hfq, a new chaperoning role: binding to messenger RNA determines access for a small RNA regulator. EMBO J. 23:396-405

26. Gerdes K, Gultyaev AP, Franch T, Pedersen K, Mikkelsen ND. 1997. Antisense RNA-regulated programmed cell death. Annu. Rev. Genet. 31:1-31

27. Gervais FG, Phoenix P, Drapeau GR. 1992. The $r \operatorname{cs} B$ gene, a positive regulator of colanic acid biosynthesis in Escherichia coli, is also an activator of $f t s Z$ expression. J. Bacteriol. 174:3964-71

28. Gillet R, Felden B. 2001. Emerging views on tmRNA-mediated protein tagging and ribosome rescue. Mol. Microbiol. 42:87985

29. Gopalan V, Vioque A, Altman S. 2002. 
RNase P: variations and uses. J. Biol. Chem. 277:6759-62

30. Gottesman S. 2002. Stealth regulation: biological circuits with small RNA switches. Genes Dev. 16:2829-42

31. Gottesman S, Roche E, Zhou Y-N, Sauer RT. 1998. The ClpXP and ClpAP proteases degrade proteins with carboxyterminal peptide tails added by the SsrAtagging system. Genes Dev. 12:133847

32. Gudapaty S, Suzuki K, Wang X, Babitzke P, Romeo T. 2001. Regulatory interactions of Csr components: the RNA binding protein CsrA activates $\operatorname{csr} B$ transcription in Escherichia coli. J. Bacteriol. 183:601727

33. Hagiwara D, Sugiura M, Oshima T, Mori H, Aiba H, et al. 2003. Genome-wide analyses revealing a signaling network of the RcsC-YojN-RcsB phosphorelay system in Escherichia coli. J. Bacteriol. 185:5735-46

34. Heeb S, Blumer C, Haas D. 2002. Regulatory RNA as mediator in GacA/RsmAdependent global control of exoproduct formation in Pseudomonas fluorescens CHAO. J. Bacteriol. 184:1046-56

35. Hengge-Aronis R. 2002. Signal transduction and regulatory mechanisms involved in control of the $\sigma^{\mathrm{S}}$ (RpoS) subunit of RNA polymerase. Microbiol. Mol. Biol. Rev. 66:373-95

36. Herman C, Thevenet D, Bouloc P, Walker GC, D'Ari R. 1998. Degradation of carboxy-terminal-tagged cytoplasmic proteins by the Escherichia coli protease HflB (FtsH). Genes Dev. 12:1348-55

37. Herskovits AA, Bochkareva ES, Bibi E. 2000. New prospects in studying the bacterial signal recognition particle pathway. Mol. Microbiol. 38:927-39

38. Hsu LM, Zagorski J, Wang Z, Fournier MJ. 1985. Escherichia coli 6S RNA gene is part of a dual-function transcription unit. J. Bacteriol. 161:1162-70

39. Ikemura T, Dahlberg JE. 1973. Small ribonucleic acids of Escherichia coli. I.
Characterization by polyacrylamide gel electrophoresis and fingerprint analysis. $J$. Biol. Chem. 248:5024-32

40. Ikemura T, Dahlberg JE. 1973. Small ribonucleic acids of Escherichia coli. II. Noncoordinate accumulation during stringent control. J. Biol. Chem. 258:5033-41

41. Jackson DW, Suzuki K, Oakford L, Simecka JW, Hart ME, Romeo T. 2002. Biofilm formation and dispersal under the influence of the global regulator CsrA of Escherichia coli. J. Bacteriol. 184:290301

42. Johansson J, Cossart P. 2003. RNAmediated control of virulence gene expression in bacterial pathogens. Trends Microbiol. 11:280-85

43. Johansson J, Mandin P, Renzoni A, Chiaruttini C, Springer M, Cossart P. 2002. An RNA thermosensor controls expression of virulence genes in Listeria monocytogenes. Cell 110:551-61

44. Kandror O, DeLeon A, Goldberg AL. 2002. Trehalose synthesis is induced upon exposure of Escherichia coli to cold and is essential for viability at low temperatures. Proc. Natl. Acad. Sci. USA 99:9727-32

45. Karzai AW, Roche ED, Sauer RT. 2000. The SsrA-SmpB system for protein tagging, directed degradation and ribosome rescue. Nat. Struct. Biol. 7:449-55

46. Karzai AW, Susskind MM, Sauer RT. 1999. SmpB, a unique RNA-binding protein essential for the peptide-tagging activity of SsrA (tmRNA). EMBO J. 18: 3793-99

47. Kawano M, Oshima T, Kasai H, Mori H. 2002. Molecular characterization of long direct repeat (LDR) sequences expressing a stable mRNA encoding for a 35-aminoacid cell-killing peptide and a cis-encoded small antisense RNA in Escherichia coli. Mol. Microbiol. 45:333-49

48. Keiler KC, Waller PRH, Sauer RT. 1996. Role of a peptide tagging system in degradation of proteins synthesized from damaged messenger RNA. Science 271:99093 
49. Kiley PJ, Beinert H. 2003. The role of $\mathrm{Fe}-\mathrm{S}$ proteins in sensing and regulation in bacteria. Curr. Opin. Microbiol. 6:181-85

50. Klauck E, Bohringer J, Hengge-Aronis R. 1997. The LysR-like regulator LeuO in Escherichia coli is involved in the translational regulation of $r p o S$ by affecting the expression of the small regulatory DsrARNA. Mol. Microbiol. 25:559-69

51. Komine Y, Kitabatake M, Yokogawa T, Nishikawa K, Inokuchi H. 1994. A tRNAlike structure is present in 10Sa RNA, a small stable RNA from Escherichia coli. Proc. Natl. Acad. Sci. USA 91:922327

52. Lease RA, Belfort M. 2000. A transacting RNA as a control switch in Escherichia coli : DsrA modulates function by forming alternative structures. Proc. Natl. Acad. Sci. USA 97:9919-24

53. Lease RA, Cusick M, Belfort M. 1998. Riboregulation in Escherichia coli: DsrA RNA acts by RNA:RNA interactions at multiple loci. Proc. Natl. Acad. Sci. USA 95:12456-61

54. Lee SY, Bailey SC, Apirion D. 1978. Small stable RNAs from Escherichia coli: evidence for the existence of new molecules and for a new ribonucleoprotein particle containing 6S RNA. J. Bacteriol. 133:1015-23

54a. Lenz DH, Mok KC, Lilley BN, Kulkarni RV, Wingreen NS, Bassler BL. 2004. The small RNA chaperone Hfq and multiple small RNAs control quorum sensing in Vibrio harveyi and Vibrio cholerae. Cell 118:69-82

55. Liaw SJ, Lai HC, Ho SW, Luh KT, Wang WB. 2003. Role of RsmA in the regulation of swarming motility and virulence factor expression in Proteus mirabilis. J. Med. Microbiol. 52:19-28

56. Liu MY, Gui G, Wei B, Preston JF III, Oakford L, et al. 1997. The RNA molecule CsrB binds to the global regulatory protein CsrA and antagonizes its activity in Escherichia coli. J. Biol. Chem. 272:17502-10
57. Majdalani N, Chen S, Murrow J, St John K, Gottesman S. 2001. Regulation of RpoS by a novel small RNA: the characterization of RprA. Mol. Microbiol. 39:1382-94

58. Majdalani N, Cunning C, Sledjeski D, Elliott T, Gottesman S. 1998. DsrA RNA regulates translation of RpoS message by an anti-antisense mechanism, independent of its action as an antisilencer of transcription. Proc. Natl. Acad. Sci. USA 95:12462-67

59. Majdalani N, Hernandez D, Gottesman S. 2002. Regulation and mode of action of the second small RNA activator of RpoS translation, RprA. Mol. Microbiol. 46:813-26

60. Massé E, Escorcia FE, Gottesman S. 2003. Coupled degradation of a small regulatory RNA and its mRNA targets in Escherichia coli. Genes Dev. 17:237483

61. Massé E, Gottesman S. 2002. A small RNA regulates the expression of genes involved in iron metabolism in Escherichia coli. Proc. Natl. Acad. Sci. USA 99:462025

62. McHugh JP, Rodriguez-Quinones F, Abdul-Tehrani H, Svistunenko DA, Poole RK, et al. 2003. Global iron-dependent gene regulation in Escherichia coli: a new mechanism for iron homeostasis. J. Biol. Chem. 278:29478-86

63. McManus MT, Sharp PA. 2003. Gene silencing in mammals by small interfering RNAs. Nat. Rev. Genet. 3:737-47

64. Mizuno T, Chou M-Y, Inouye M. 1984. A unique mechanism regulating gene expression: translational inhibition by a complementary RNA transcript (micRNA). Proc. Natl. Acad. Sci. USA 81: 1966-70

65. Moll I, Afonyushkin T, Vytvytska O, Kaberdin VR, Blasi U. 2003. Coincident Hfq binding and RNase E cleavage sites on mRNA and small regulatory RNAs. RNA 9:1308-14

66. Moll I, Leitsch D, Steinhauser T, Blasi 
U. 2003. RNA chaperone activity of the Sm-like Hfq protein. EMBO Rep. 4:284 89

67. Møller T, Franch T, Hojrup P, Keene DR, Bachinger HP, et al. 2002. Hfq: a bacterial Sm-like protein that mediates RNA-RNA interaction. Mol. Cell 9:23-30

68. Møller T, Franch T, Udesen C, Gerdes K, Valentin-Hansen P. 2002. Spot 42 RNA mediates discoordinate expression of the E. coli galactose operon. Genes Dev. 16:1696-706

69. Muffler A, Fischer D, Hengge-Aronis R. 1996. The RNA-binding protein HF-I, known as a host factor for phage $\mathrm{Q} \beta$ RNA replication, is essential for $r p o S$ translation in Escherichia coli. Genes Dev. 10:1143-51

70. Nakao H, Watanabe $H$, Nakayama S, Takeda T. 1995. yst gene expression in Yersinia enterocolitica is positively regulated by a chromosomal region that is highly homologous to Escherichia coli host factor 1 gene $(h f q)$. Mol. Microbiol. 18:859-65

70a. Nudler E, Mironov AS. 2004. The riboswitch control of bacterial metabolism. Trends Biochem. Sci. 29:11-17

71. Pedersen K, Gerdes K. 1999. Multiple hok genes on the chromosome of Escherichia coli. Mol. Microbiol. 32:1090-102

72. Pernestig A-K, Georgellis D, Romeo T, Suzuki K, Tomenius H, et al. 2003. The Escherichia coli BarA-UvrY twocomponent system is needed for efficient switching between glycolytic and gluconeogenic carbon sources. J. Bacteriol. 185:843-53

73. Pratt LA, Hsing W, Gibson KE, Silhavy TJ. 1996. From acids to osmZ: multiple factors influence synthesis of the $\mathrm{OmpF}$ and OmpC porins in Escherichia coli. Mol. Microbiol. 20:911-17

74. Repoila F, Gottesman S. 2001. Signal transduction cascade for regulation of RpoS: temperature regulation of DsrA. $J$. Bacteriol. 183:4012-23

75. Repoila F, Gottesman S. 2003. Tempera- ture sensing by the $d s r A$ promoter. J. Bacteriol. 185:6609-14

76. Repoila F, Majdalani N, Gottesman S. 2003. Small non-coding RNAs, coordinators of adaptation processes in Escherichia coli: the RpoS paradigm. Mol. Microbiol. 48:855-61

77. Rivas E, Klein RJ, Jones TA, Eddy SR. 2001. Computational identification of noncoding RNAs in E. coli by comparative genomics. Curr. Biol. 11:1369-73

78. Romeo T. 1998. Global regulation by the small RNA-binding protein CsrA and the non-coding RNA molecule CsrB. Mol. Microbiol. 29:1321-30

79. Roop RM II, Gee JM, Robertson GT, Richardson JM, Ng W-L, Winkler ME. 2003. Brucella stationary-phase gene expression and virulence. Annu. Rev. Microbiol. 57:57-76

80. Sahagan B, Dahlberg JE. 1979. A small, unstable RNA molecule of Escherichia coli: Spot 42 RNA. II. Accumulation and distribution. J. Mol. Biol. 131:593-605

81. Sauter C, Basquin J, Suck D. 2003. Sm-like proteins in eubacteria: the crystal structure of the Hfq protein from Escherichia coli. Nucleic Acids Res. 31:4091-98

82. Schell MA. 1993. Molecular biology of the LysR family of transcriptional regulators. Annu. Rev. Microbiol. 47:597-626

83. Schumacher MA, Pearson RF, Moller T, Valentin-Hansen P, Brennan RG. 2002. Structures of the pleiotropic translational regulator Hfq and an Hfq-RNA complex: a bacterial Sm-like protein. EMBO J. 21:3546-56

84. Sledjeski DD, Gottesman S. 1995. A small RNA acts as an antisilencer of the H-NS-silenced rcsA gene of Escherichia coli. Proc. Natl. Acad. Sci. USA 92:20037

85. Sledjeski DD, Gupta A, Gottesman S. 1996. The small RNA, DsrA, is essential for the low temperature expression of RpoS during exponential growth in Escherichia coli. EMBO J. 15:3993-4000 
86. Sledjeski DD, Whitman C, Zhang A. 2001. Hfq is necessary for regulation by the untranslated RNA DsrA. J. Bacteriol. 183:1997-2005

87. Sonnleitner E, Hagens S, Rosenau F, Wilhelm S, Habel A, et al. 2003. Reduced virulence of a $h f q$ mutant of Pseudomonas aeruginosa 01. Microb. Pathog. 35:21728

88. Stormo G. 2003. New tricks for an old dogma: Riboswitches as cis-only regulatory systems. Mol. Cell 11:1419-20

89. Storz G. 2002. An expanding universe of noncoding RNAs. Science 296:126063

90. Sukhodolets MV, Garges S. 2003. Interaction of Escherichia coli RNA polymerase with the ribosomal protein $\mathrm{S} 1$ and the Smlike ATPase Hfq. Biochemistry 42:802234

91. Sun X, Zhulin I, Wartell RM. 2002. Predicted structure and phyletic distribution of the RNA-binding protein Hfq. Nucleic Acids Res. 30:3662-71

92. Suzuki K, Wang X, Weilbacher T, Pernestig AK, Melefors O, et al. 2002. Regulatory circuitry of the CsrA/CsrB and BarA/UvrY systems of Escherichia coli. J. Bacteriol. 184:5130-40

93. Tetart F, Bouché JP. 1992. Regulation of the expression of the cell-cycle gene $f t s Z$ by DicF antisense RNA. Division does not require a fixed number of FtsZ molecules. Mol. Microbiol. 6:615-20

94. Tjaden B, Saxena RM, Stolyar S, Haynor DR, Kolker E, Rosenow C. 2002. Transcriptome analysis of Escherichia coli using high density oligonucleotide probe arrays. Nucleic Acids Res. 30:373238

95. Tsui H-CT, Leung H-CE, Winkler ME. 1994. Characterization of broadly pleiotropic phenotypes caused by an $h f q$ insertion mutation in Escherichia coli K12. Mol. Microbiol. 13:35-49

96. Tu G-F, Reid GE, Zhang J-G, Moritz RL, Simpson RJ. 1995. C-terminal extension of truncated recombinant proteins in $E s$ - cherichia coli with a 10Sa RNA decapeptide. J. Biol. Chem. 270:9322-26

97. Urbanowski ML, Stauffer LT, Stauffer GV. 2000. The $g c v B$ gene encodes a small untranslated RNA involved in expression of the dipeptide and oligopeptide transport systems in Escherichia coli. Mol. Microbiol. 37:856-68

97a. Valentin-Hansen P, Eriksen M, Udesen C. 2004. The bacterial Sm-like protein Hfq: a key player in RNA transactions. Mol. Microbiol. 51:1525-33

98. Valle M, Gillet R, Kaur S, Henne A, Ramakrishnan V, Frank J. 2003. Visualizing tmRNA entry into a stalled ribosome. Science 300:127-30

99. Vecerek B, Moll I, Afonyushkin T, Kaberdin V, Blasi U. 2003. Interaction of the RNA chaperone Hfq with mRNAs: direct and indirect roles of $\mathrm{Hfq}$ in iron metabolism of Escherichia coli. Mol. Microbiol. 50:897-909

100. Vogel J, Bartels V, Tang HH, Churakov G, Slagter-Jager JG, et al. 2003. RNomics in Escherichia coli detects new sRNA species and indicates parallel transcriptional output in bacteria. Nucleic Acids Res. 31:6435-43

101. Vytvytska O, Moll I, Kaberdin VR, von Gabain A, Blasi U. 2000. Hfq (HF1) stimulates ompA mRNA decay by interfering with ribosome binding. Genes Dev. 14:1109-18

102. Wagner EGH, Brantl S. 1998. Kissing and RNA stability in antisense control of plasmid replication. Trends Biochem. Sci. 23:451-54

103. Wagner EGH, Simons RW. 1994. Antisense RNA control in bacteria, phages, and plasmids. Annu. Rev. Microbiol. 48:713-42

104. Walker GC. 1987. The SOS response of Escherichia coli. In Escherichia coli and Salmonella typhimurium: Cellular and Molecular Biology, ed. FC Neidhardt, JL Ingraham, KB Low, B Magasanik, M Schaechter, HE Umbarger, pp. 1346-57. Washington, DC: Am. Soc. Microbiol. 
105. Wassarman KM, Repoila F, Rosenow C, Storz G, Gottesman S. 2001. Identification of novel small RNAs using comparative genomics and microarrays. Genes Dev. 15:1637-51

106. Wassarman KM, Storz G. 2000. 6S RNA regulates $E$. coli RNA polymerase activity. Cell 101:613-23

107. Weilbacher T, Suzuki K, Dubey AK, Wang X, Gudapaty S, et al. 2002. A novel sRNA component of the carbon storage regulatory system of Escherichia coli. Mol. Microbiol. 48:657-70

108. Weisberg RA, Storz G. 2002. Take your vitamins with a pinch of RNA. Mol. Cell 10:1266-68

109. Williams KP. 2002. The tmRNA website: invasion by an intron. Nucleic Acids Res. 30:179-82

110. Williams KP, Bartel DP. 1996. Phylogenetic analysis of tmRNA secondary structure. RNA 2:1306-10

111. Withey JH, Friedman DI. 2003. A salvage pathway for protein synthesis: tmRNA and trans-translation. Annu. Rev. Microbiol. 57:101-23
112. Worhunsky DJ, Godek K, Litsch S, Schlax PJ. 2003. Interactions of non-coding RNA DsrA and RpoS mRNA with the 30S ribosomal subunit. J. Biol. Chem. 278:1581524

113. Zhang A, Altuvia S, Tiwari A, Argaman L, Hengge-Aronis R, Storz G. 1998. The $\operatorname{oxy} S$ regulatory RNA represses rpoS translation by binding $\mathrm{Hfq}(\mathrm{HF}-1)$ protein. EMBO J. 17:6061-68

114. Zhang A, Wassarman KM, Ortega J, Steven AC, Storz G. 2002. The Sm-like Hfq protein increases OxyS RNA interaction with target mRNAs. Mol. Cell 9:1122

115. Zhang A, Wassarman KM, Rosenow C, Tjaden BC, Storz G, Gottesman S. 2003. Global analysis of small RNA and mRNA targets of Hfq. Mol. Microbiol. 50:111124

116. Wilderman PJ, Sowa NA, FitzGerald DJ, FitzGerald PC, Gottesman S, et al. 2004. Identification of tandem duplicate regulatory small RNAs in Pseudomonas aeruginosa involved in iron homeostasis. Proc. Natl. Acad. Sci. USA 101:9792-97 


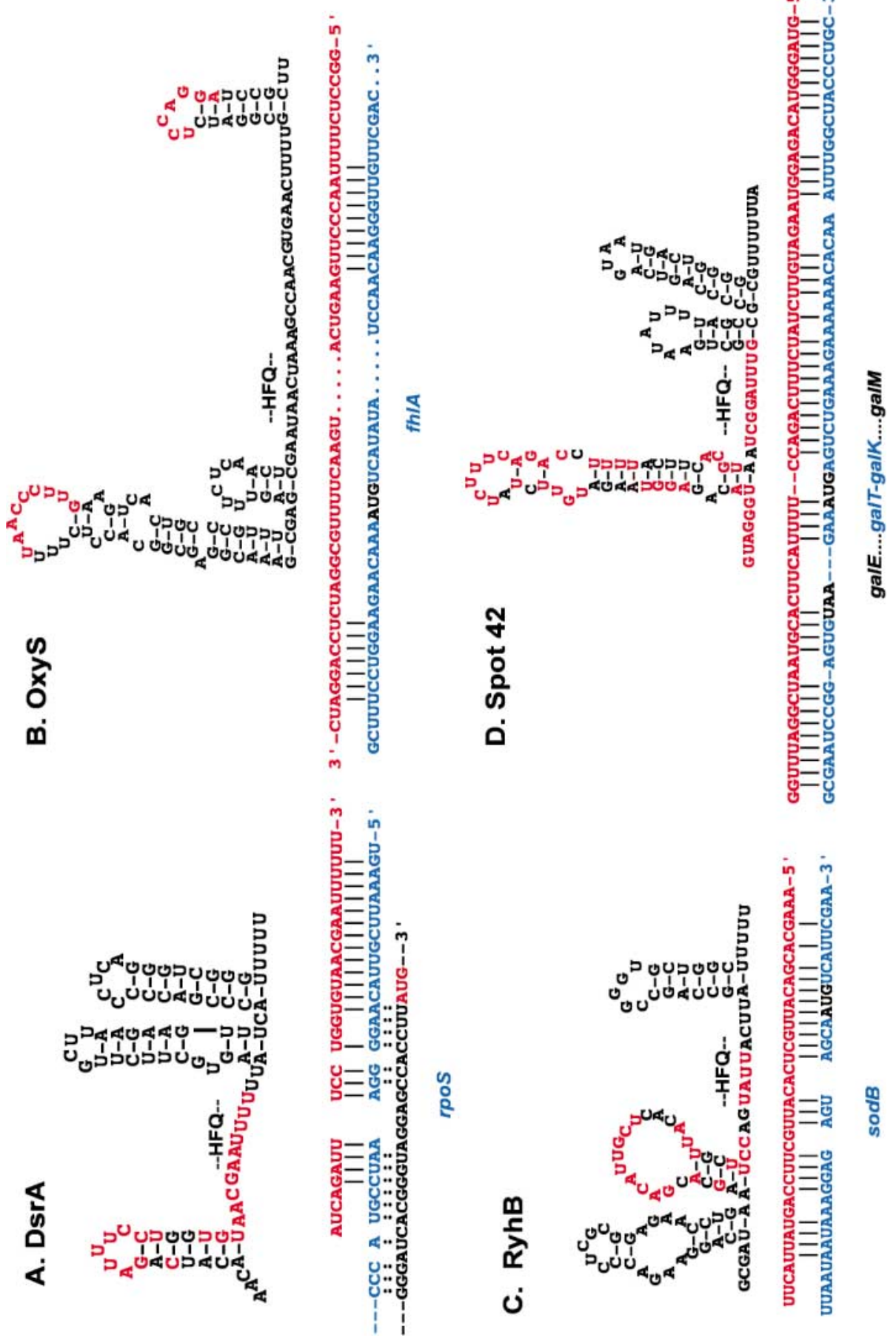


Figure 1 sRNAs that act by pairing. Each panel illustrates the structure of the sRNA, as determined by in vitro probing experiments. The bases that pair with the target shown are in red. The single-stranded regions that bind Hfq and/or are protected by Hfq are indicated by a --Hfq--. Below each sRNA is a linear representation of the pairing of the sRNA (red) with a target (blue). The AUG in the target sequences are shown in black. In all these cases, some part of the pairing has been experimentally tested; in none has the full pairing been tested. (A) DsrA. The structure is as determined by (12). The target, rpoS, is positively regulated by DsrA, by pairing to the upstream RNA (blue); alternatively, the blue strand pairs with the black strand to inhibit ribosome binding and translation (indicated by a colon between the paired nucleotides) (76). The blue and black strands are connected by an additional 63 nucleotides. $(B)$ OxyS. The structure and pairing is as determined by $(2,3)$; Hfq binding is from (114). (C) RyhB. The structure and Hfq binding is from (25); the pairing is an extension of that determined by Geissmann \& Touati on the basis of visual examination of the sequence. $(D)$ Spot 42 . The structure and Hfq binding is as determined by $(67,68)$. The UAA (black) is the terminator codon for galT; the AUG is the start codon for galK. 
药

Annual Review of Microbiology

Volume 58, 2004

\section{CONTENTS}

FrontisPiECE, Arnold L. Demain

Pickles, Pectin, And Penicillin, Arnold L. Demain

xii

Anaerobic Microbial Dehalogenation, Hauke Smidt and

Willem M. de Vos

SignALING In MYXobaCteria, Dale Kaiser

AnaERobic Oxidation of Methane and Ammonium, Marc Strous and Mike S.M. Jetten

SElection For Gene Clustering By TANDEM DupliCATION, Andrew B. Reams and Ellen L. Neidle

THE VibRio SHILOI/OCULINA PATAGONICA MODEL SySTEM OF CORAL BLEACHING, Eugene Rosenberg and Leah Falkovitz.

StATIONARY-Phase Physiology, Thomas Nyström

Viral ERror Catastrophe By Mutagenic Nucleosides, Jon P. Anderson, Richard Daifuku, and Lawrence A. Loeb

The Ecology and Genetics of Microbial Diversity, Rees Kassen and Paul B. Rainey

Ribosomal CRYSTALlography: INITIATION, PEPTIDE BOND FoRMATION, AND AMINO ACID POLYMERIZATION ARE HAMPERED By ANTIBIOTICS, Ada Yonath and Anat Bashan

HerPes Vector-Mediated Gene TRansfer in Treatment of Diseases of the Nervous System, Joseph C. Glorioso and David J. Fink

EARLy MoleCUlaR INVESTIGATIONS OF LICHEN-FORMING SYMBIONTS: 1986-2001, Paula T. DePriest

THE SMALL RNA REgUlators OF ESCHERICHIA COLI: ROLES AND MECHANISMS, Susan Gottesman

JOHNE'S DiSEASE, INFLAMMATORY BOWEL DISEASE, AND MYCOBACTERIUM PARATUBERCULOSIS, Ofelia Chacon, Luiz E. Bermudez, and

Raúl G. Barletta

Molecular and Cellular Basis of Bartonella Pathogenesis, Christoph Dehio 
Cell-Mediated Immunity and the Outcome of HePatitis C Virus

InFECTION, Naglaa H. Shoukry, Andrew G. Cawthon, and

Christopher M. Walker

RECENT ADVANCES IN THE CHARACTERIZATION OF AMBIENT PH REGULATION OF GENE EXPRESSION IN FILAMENTOUS FunGI AND YeASTS, Miguel A. Peñalva and Herbert N. Arst, Jr.

BIOSYNTHESIS OF NONRIBOSOMAL PEPTIDES, Robert Finking and Mohamed A. Marahiel

CirCADian RHYTHMS IN Microorganisms: NeW CompleXities, Patricia L. Lakin-Thomas and Stuart Brody

The Cellulosomes: Multienzyme Machines for Degradation of Plant Cell Wall Polysaccharides, Edward A. Bayer, Jean-Pierre Belaich, Yuval Shoham, and Raphael Lamed

Biophysical ANALySES of Designed AND SELECTED Mutants of Protocatechuate 3,4-Dioxygenase, $C$. Kent Brown, Matthew W. Vetting, Cathleen A. Earhart, and Douglas H. Ohlendorf

MoleCUlar DetERMinANTS OF LISTERIA MONOCYTOGENES VIRULENCE, Olivier Dussurget, Javier Pizarro-Cerda, and Pascale Cossart

BACTERIAL IRON SOURCES: From Siderophores to HeMOPHORES, Cécile Wandersman and Philippe Delepelaire

ENDANGERED ANTARCTIC ENVIRONMENTS, Don A. Cowan and Lemese Ah Tow

INDEXES

Subject Index

Cumulative Index of Contributing Authors, Volumes 54-58

735

Cumulative Index of Chapter Titles, Volumes 54-58

738

\section{ERRATA}

An online log of corrections to Annual Review of Microbiology chapters may be found at http://micro.annualreviews.org/ 